Mal J Nutr 27(3): 507-530, 2021

\title{
REVIEW
}

\section{Status of probiotic regulations in Southeast Asia countries}

\author{
Tee E Siong ${ }^{1,2}$, Hardinsyah ${ }^{1,3} \&$ Cyndy Au Sook Sum ${ }^{1,4}$ \\ ${ }^{1}$ Southeast Asia Probiotics Scientific \& Regulatory Experts Network; ${ }^{2}$ Nutrition Society \\ of Malaysia; ${ }^{3}$ IPB University Indonesia; ${ }^{4}$ Singapore Management University
}

\begin{abstract}
This review summarises the key components of the available probiotic regulations in six Southeast Asia countries (Indonesia, Malaysia, Philippines, Singapore, Thailand and Vietnam). Diverse approaches have been undertaken by the countries in regulating the marketing and sale of probiotics in foods and health supplements. Only Indonesia, Malaysia, Philippines and Thailand have enacted specific regulations which include their respective legal definition of probiotics. Only Malaysia, Philippines and Thailand publish a list of microorganisms permitted to be used as probiotics in foods or health supplements; the approved microorganisms are not harmonised among these countries. All six countries allow the application for new microorganisms to be used, but have adopted differing requirements and approaches. A common requirement is that all applications must be accompanied by scientific data to demonstrate clinically that the microorganisms are safe and provide health benefits. All the countries, except Indonesia and Vietnam permit the use of a small number of pre-approved generic function claims. It is noted that the countries have different specific labelling requirement for products containing probiotics. The divergent probiotic regulations in the region, either for foods or health supplements, creates inconsistencies and difficulties for all stakeholders including regulators, academia, industries and consumers, as well as impacting trade among countries. This review highlights the importance of having regulatory control to ensure consumers have access to safe, genuine and efficacious probiotic products. We propose working towards a harmonised probiotics regulation in the region to enable further development and progress of probiotics in the region.
\end{abstract}

Keywords: probiotics, regulations, harmonisation, health supplements, functional foods

\section{INTRODUCTION}

The Food and Agriculture Organization/ World Health Organization (FAO/WHO) Joint Expert Consultation report has defined probiotics as live microorganisms which when administered in adequate amounts confer a health benefit on the host (FAO/WHO, 2001). This definition was "reinforced as relevant and sufficiently accommodating for current and anticipated applications" by a consensus statement of the

\footnotetext{
*Corresponding author: Dr Tee E Siong

Co-chair, Southeast Asia Probiotics Scientific \& Regulatory Experts Network

President, Nutrition Society of Malaysia

Email: president@nutriweb.org.my

doi: https://doi.org/ 10.31246/mjn-2021-27-3-probiotic-regulations-review
} 
International Scientific Association for Probiotics and Prebiotics (ISAPP) (Hill et al., 2014). Probiotics have become an increasingly popular functional foods, with growing clinical evidence supporting the effectiveness of probiotics in general health maintenance and disease treatment, especially conditions related to digestive tract, the immune system and respiratory functions (Nomoto, 2021; Hill et al., 2014).

According to the Mordor Intelligence (2021) report, during the forecast period 2020-2025, Asia Pacific is the largest as well as the fastest growing probiotics market. Probiotics have become a part of functional foods and beverages, consumed by people of all ages. The exogenous shock presented by the COVID-19 pandemic in early 2020 has contributed to a surge in demand for products that provide immune health, including probiotics. According to the report, the complexity of regulatory, legislative, and technological aspects may be major hurdles impeding market growth. Hill et al. (2014) noted that amidst the rapid progress in clinical evidence and growth in probiotic products, misuse of the term probiotic has become a major issue, with many products exploiting the term without meeting the required criteria.

There is clearly a need for regulatory control of probiotics to facilitate research and development in probiotics and to make sure effective and safe products reach the consumers. Regulations should clearly spell out the definition of probiotics, their characteristics, safety requirements and specific labelling requirements of foods and dietary supplements containing these live microbes.

In view of these developments, the Southeast Asia Probiotics Scientific and Regulatory Experts Network (SEA PROBIOTICS SREN) carried out a review of the available probiotic regulations in countries in the region, covering the use of probiotics in foods and beverages as well as in dietary or health supplements.

\section{METHODOLOGY}

A template was prepared by the authors, with the following key aspects of the probiotic regulations or documents:

- regulatory framework including legal definition of probiotics

- requirement for minimum number of probiotic microorganisms

- positive list for approved probiotic microorganisms

- requirements and procedure for applications for use of new probiotics

- specific labelling requirements for probiotic products

- probiotic health claims and procedure for application

Regulatory officials and relevant regulatory experts from Indonesia, Malaysia, Philippines, Thailand and Vietnam who have been participating in periodic meetings of the SEA PROBIOTICS SREN were requested to assist in providing the information required in the template based on the available official documents in their respective country. These officials and experts were also requested to provide the official regulations or documents related to the use of probiotics as an ingredient in foods and beverages, as well as for use as dietary or health supplements. For the other countries in Southeast Asia (SEA), a search for any relevant documents were made on the official regulatory websites.

The authors scrutinised the entries for the template and compared these with the information in the official documents from the regulatory authorities. After compilation and editing by the authors, they were returned to the officials for verification. 


\section{RESULTS}

Regulations or related documentations (for example guideline, decree or circular) for the control of the sale and marketing of probiotics in foods and dietary or health supplements were obtained from six countries in SEA, namely Indonesia, Malaysia, Philippines, Singapore, Thailand and Vietnam. For convenience of presenting the regulatory status of the use of probiotics in foods and beverages (hereinafter referred to as foods) as well as in dietary/health supplements (hereinafter referred to as dietary supplements) in the six countries, this review is presented based on the key aspects as listed in the methodology section above.

\section{Regulatory framework including legal definition of probiotics}

Probiotic-containing foods and health supplements in Indonesia are regulated by two different divisions of the National Agency for Drug and Food Control (NADFC).

The sale of probiotics as food is being regulated under the Directorate for food standardization. A specific regulation on probiotic-containing foods was enacted in early 2016 concerning Controlling of Claims on Processed Food Label and Advertising, specifically Annex XI on Guidelines for the Assessment of the Use of Probiotics in Processed Food (NADFC, 2016). In this regulation, probiotics are defined as "Live microorganisms which when administered in adequate amounts confer a health benefit on the host". Probiotic-containing foods under this regulation include fermentation products containing one or more probiotic bacteria; or dried food products containing one or more dried bacteria in the form of granules or powder which can be consumed as a food or beverage; or non-fermented liquid food product containing one or more probiotic bacteria.

On the other hand, probiotics as supplements are regulated under Directorate for Traditional Medicine, Health Supplement and Cosmetics Standardization. A recently enacted Regulation 17 of 2021 serves as a Guideline on Evaluation of Health Supplement Products Containing Probiotics for NADFC in registering new products and the business community (NADFC, 2021). The legal definition for probiotics in health supplements is the same as for probiotics in foods.

In Malaysia, probiotics can be used in food, beverages, and health supplements, and regulated by two different divisions of the Ministry of Health Malaysia.

The Food Safety and Quality Division (FSQD), Ministry of Health Malaysia is the regulatory authority responsible for sale of probiotics in foods and beverages. A specific regulation (Regulation 26A Probiotic culture) to permit probiotic cultures to be added to foods and regulate their use was gazette in April 2017, under Malaysia Food Regulation 1985 (MOH Malaysia, 2017). Through this regulation, the legal definition given to probiotic culture is: live microorganisms which when administrated in adequate numbers confer health benefits on the host'.

The control of probiotic health supplements is under the National Pharmaceutical Regulatory Agency (NPRA), Ministry of Health Malaysia. A specific regulation on probiotic supplements has not been developed. Probiotics in health supplements fall under the definition of "product" in Control of Drugs and Cosmetics Regulations (CDCR) (MOH Malaysia, 1984). The term 'product' as used in this law refers to 'a drug to be used as an 
ingredient of a preparation for a medicinal purpose'. In this regard, probiotics fall under the medicinal purpose for 'general maintenance or promotion of health or wellbeing'. Probiotics are listed as health supplements in the Drug Registration Guidance Document (MOH Malaysia, 2021). The definition for probiotic in health supplements follows the generally recognised definition by WHO: "live microorganisms which when administered in adequate amounts confer a health benefit on the host".

The sale and use of probiotics in foods and dietary supplements in the Philippines are regulated by the Food and Drug Administration (FDA) Philippines through regulation Bureau of Food and Drug (BFAD) Circular No. 16s 2004 (BFAD, 2004). Through this regulation, Philippines has provided the following definition for probiotics, which followed the definition by Guarner \& Schaafsma (1998): "a dietary supplement based on living organisms which when administered in sufficient quantity, has a beneficial effect on the host organism, improving the equilibrium of the intestinal microflora". There is no requirement for minimum number of microorganisms that must be present.

The use of probiotics in Singapore can be regulated either under the food regulations or as health supplements, by two separate authorities.

The sale of probiotic-containing foods is regulated by the Singapore Food Agency (SFA). However there is no specific regulation on probiotics and current food regulations do not use or define the term 'probiotics'. Nevertheless, strains of bifidobacteria and lactobacillus that have a proven long history of safe use may be used as probiotics in suitable categories of food products. These include cultured milk drink and yoghurt (SFA, 2021).

Complementary health products containing probiotics (classified as health supplements) are under the purview of the Health Sciences Authority (HSA) which has not provided a specific regulation or definition of probiotics (HSA, 2021). Health supplements are not subject to product approvals, registration nor dealer licensing. Dealers of health supplements are responsible for the safety and quality of their products and compliance with the guidelines prescribed by the HSA.

The FDA, Ministry of Public Health, Thailand is the regulatory authority responsible for probiotics classified as food or dietary supplement. Two Notifications of the Ministry of Public Health, no. 339 (2011) and no. 346 (2012) regulate the use of probiotic microorganisms in both food and supplements (MoPH, 2011; MoPH, 2012). Through Notification no. 339, Thailand has provided the following legal definition for probiotics: "Probiotic Microorganisms means viable microorganisms that are beneficial to body if intake in sufficient amount" (MoPH, 2011).

In Vietnam, there is no specific regulation or legal definition of probiotics. The sale of probiotics in foods and supplements is regulated through several government agencies, including the Vietnam Food Administration (VFA) and inspectors of the Ministry of Health, Department of Health and Food Safety Management Agencies, Vietnam Directorate of Market Surveillance (Ministry of Industry and Trade) and its agencies at the provincial levels. The Food Safety Law of Vietnam has listed probiotics as a dietary supplement (Decree 15/2018/ND-CP) (Government of Vietnam, 2018). More details on the management of probiotics under functional foods, which includes supplemented foods and dietary supplements is provided in Circular No. 43/2014/TT-BYT (MOH Vietnam, 2014).

Supplemented food has been defined as conventional food supplemented with micronutrients and other healthful 
components for the body such as vitamins, minerals, amino acids, fatty acids, enzymes, probiotics, prebiotics and other biologically active substances. Dietary supplement refers to a product used as a supplement to the daily diet to maintain, enhance and improve health functions and disease risk reduction, and can be in the form of soft gels, pellets, tablets, granules, powder, liquid and other dosage form divided into smaller doses (MOH Vietnam, 2014).

\section{Requirement for minimum number of probiotic microorganisms}

NADFC Indonesia has indicated that if there is no claim for a probioticcontaining food product, it is not required to declare the number of organisms on the label (NADFC, 2016). On the other hand, if there is a claim on the label, it is required to declare the number of organisms in terms of colony forming unit, $\mathrm{cfu} / \mathrm{g}$ or $\mathrm{ml}$, based on the clinical study for that claim.

The NADFC guideline for health supplements has indicated that the probiotics must be live cultures, but has not specified the minimum number of microorganisms that must be present in the product.

For Malaysia, one of the conditions in the FSQD regulation is that the probiotic cultures added shall remain viable and the viable probiotic count shall not be less than $10^{6} \mathrm{cfu} / \mathrm{ml}$ or $\mathrm{cfu} / \mathrm{g}$ during the shelf life of such food. For probiotic health supplements, NPRA has not indicated that there must be a minimum number of microorganisms in the products.

The BFAD circular of the Philippines does not specify the minimum number of probiotics that must be present in a food or dietary supplement product (BFAD, 2004).

The minimum number of viable probiotic microorganisms is not specified in the singapore food regulations.
The onus is on companies to ensure that the viable count of the probiotic microorganisms present in the product throughout its shelf life is able to bring about the claimed effect. The HSA too does not specify the minimum number of organisms that must be in a health supplement that contains probiotics. Dealers are required to ensure that the probiotic strains used and the recommended doses are safe and meet the dosing recommendations stated in the evidence or references for the claimed intended effects for the target consumers.

In Notification no. 339 of 2011 of Thailand, the number of viable probiotic microorganisms in the product shall be not less than $10^{6} \mathrm{cfu} / \mathrm{g}$ food at the end of its shelf life. In products in which there are more than one kind of probiotics used, each kind of microorganisms shall be viable and not less than $10^{6} \mathrm{cfu} / \mathrm{g}$ food at the end of its shelf life.

In Vietnam, there is no specific requirement to declare the minimum number on the label. But the minimum number must be declared if required by Codex or other international organisations or if there is a dosage recommendation.

\section{Availability of positive list of} approved probiotic microorganisms Indonesia has not issued a positive list of approved probiotic species/ strains for use in foods (NADFC, 2016). The recent regulation for health supplements containing probiotics has also not provided a list of approved microorganisms (NADFC, 2021. Manufacturers or importers may apply to the NADFC for use of probiotic microorganisms (see next section).

The FSQD Malaysia currently lists 13 Bifidobacterium strains and 19 Lactobacillus strains in regulation 26A that may be recognised as probiotic cultures and permitted to be added to 
foods (Table 1) (MOH Malaysia, 2017). Manufacturers or importers may apply for additional probiotics to be added to the list (see next section).

In terms of probiotic use in health supplements in Malaysia, NPRA has not provided a list of probiotic microorganisms approved to be used (MOH Malaysia, 1984). However, probiotics allowed in the registered health supplements that are currently on the market can be checked in NPRA website under product search. Prior approval from NPRA is required before the use of probiotics strain in health supplements that are not currently registered (see next section).

An approved list of five genera/ species of microorganisms to be used as probiotics in the Philippines is provided in the Bureau Circular (BFAD, 2004). Current list comprises Lactobacilli, Bifidobacteria, non-pathogenic strains of Streptococcus, Sacchromamyces boulardi and Bacillus causii (Table 1).

SFA has not published a list of probiotics allowed for use in foods in Singapore. However, strains of bifidobacteria and lactobacillus that have a proven long history of safe use in food (such as Bifidobacterium bifidum, Lactobacillus acidophilus, Lactobacillus delbrueckii, Lactobacillus casei Shirota strain) are allowed to be used as probiotics in suitable categories of food products (SFA, 2021).

Similarly, HSA Singapore has not published a list of approved probiotic microorganisms in health supplements (HSA, 2021). Health supplements containing probiotics are permitted in Singapore. As previously indicated, they are not subject to approvals and licensing by HSA for their importation, manufacture and sales.

The Thailand FDA Notification no. 339 of 2011 has provided a list of 23 species of microorganisms for use on foods and supplements. This comprises
9 Bifidobacterium, 2 Enterococcus, 9 Lactobacillus, 1 Propionibacterium, 1 Staphylococcus, and 1 Saccharomyces species (Table 1) (MoPH, 2011).

Vietnam Food Authority (VFA) has not established a positive list of approved probiotic microorganisms for use in foods and supplements. Manufacturers may register a bacteria strain for use under supplemented food or as a health supplement (see next section).

\section{Requirements and procedure for applications for use of new probiotics} In Indonesia, manufacturers or importers may apply to the NADFC for use of microorganisms as probiotics in foods. Each new probiotic strain must go through a review process, which includes detailed functional characterisation and safety evaluation before it can be used in food (details of requirements given in Table 2) (NADFC, 2016). It is mandatory for companies/manufacturers to conduct phase two clinical trials on Indonesian population in Indonesia. The regulation also stipulates that the trials shall be conducted in each finished product where data obtained from one type of processed food containing specific probiotics cannot be extrapolated to other processed food products containing the same probiotic strains. Details of the assessment process, including clinical trial requirements are given in Annex XII of the regulation (NADFC, 2016). NADFC has in place a process to receive an review all applications. Data in all submissions will first be verified by the Agency and assessed based on the above mentioned Annex.

Similarly, manufacturers may apply for a new probiotic strains to be used in health supplement products. All applicants must be supported by documents that demonstrate safety and beneficial effects and quality of the products. The NADFC (2021) guideline has provided a flow chart for the 


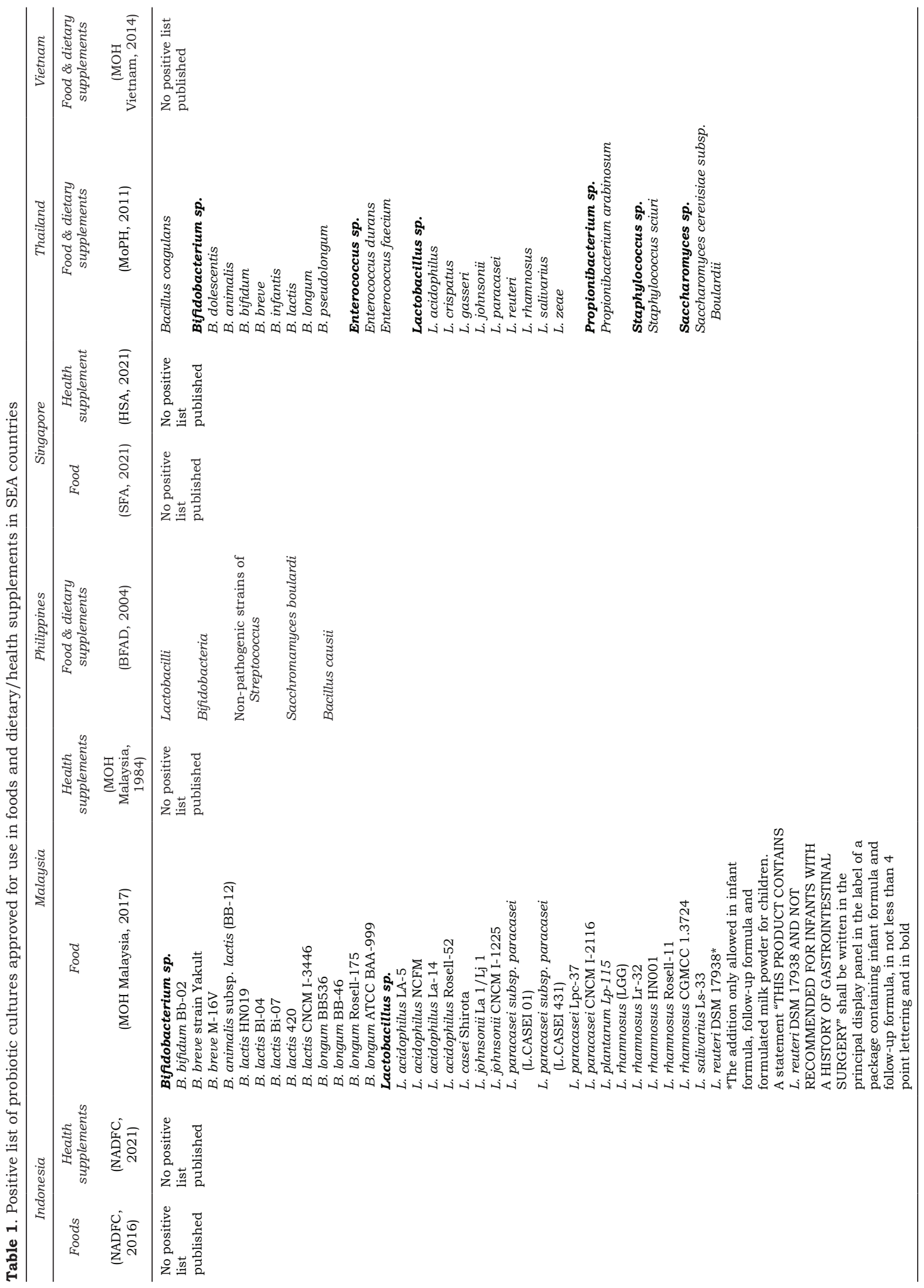


categorisation of a probiotic product to determine if it is to be registered as a drug or a health supplement. A separate flow chart provides the principles of assessment of such products, including probiotic strain identification, functional characterisation and quality evaluation. The requirements for the phases of clinical trials for the evaluation of health effects of probiotics are also provided in the chart (Table 2).

In addition to the 23 probiotic strains in the positive list in the Malaysia probiotic regulation, food companies may apply to FSQD for additional strains to be added to the list. Applications can be made using an application form that is available from FSQD website: http:/ / fsq. moh.gov. my/v6/xs/page.php?id=72. FSQD takes into consideration the probiotic characteristics, history of consumption, the safety of the strain to human and beneficial to health as demonstrated in human studies. Several safety requirements and other supporting requirements that should be documented for FSQD review are listed in Table 2 . FSQD emphasises that the documents provided must be comprehensive to fulfil all the requirements and must be strain specific.

In the FSQD regulatory review process, scientific data and supporting documents submitted would first be screened by a regulatory officer before being reviewed extensively by an expert working group on microbiology. The expert working group presents all proposals for review by the Advisory Committee on the Food Legislation, and lastly the approved document is handled by the legal department for gazettement.

Probiotic health supplements that are not yet registered by the NPRA Malaysia must apply for registration. Applications are required to meet the strain specific safety and health beneficial requirements as demonstrated in human studies, as well as the requirement on probiotic characterisation (Table 2). NPRA has also outlined the documents required to support the safety of probiotics as well as other requirements for the use of probiotics in health supplements (Table 2) (MOH Malaysia 2021). The review process for probiotics in health supplements involves four steps: screening of product registration application, evaluation of product registration application, table application in product evaluation committee meeting and table application in drug control authority meeting in which a decision on approval or rejection of product registration will be taken.

In the Philippines, companies may apply for the use of probiotics not in the current list of BFAD (2004) using the electronic registration system under FDA Circular 2016-014 (FDA, 2016). The new bacterial strain must provide evidence of safe use as food supplement, undergo probiotic characterisation, and demonstrate effectiveness as a probiotic (Table 2). The review process undertaken in the evaluation of probiotic food use include strain identification through phenotypic and genotypic methods, deposition of strain in international culture collection, determination of functional characterisation of identified strain through in vitro tests and animal studies, and safety assessment of the strain through in vitro tests and/or animal studies as well as phase one human study.

For the use of new microorganisms for use as probiotics in foods in Singapore, an application may be submitted to SFA. All needed documents must be submitted, including complete identification and characterisation of the microorganism. Manufacturers are required to ensure that the strains used, as well as the quantities of probiotic bacteria present in their food products are safe and suitable for consumption by the target group of consumers and are sufficient throughout its shelf life to 
deliver the intended function as claimed. Details of requirements are given in Table 2.

The review process for the assessment of a new microorganism for use in food can be summarised into three steps: (1) the applicant submits an application for the assessment of a new microorganism to SFA for review; (2) SFA reviews the information provided and may request further information from the applicant; and (3) if the outcome of the review is positive, SFA issues an approval letter to the applicant for the use of the new microorganism in food.

The sale of health supplements in Singapore, including those containing probiotics, are not subject to pre-market approvals, registration nor dealer licensing by HSA. Nevertheless, the onus of responsibility on the safety and quality of their health supplement products rest on importers. Thus, for probioticcontaining health supplements, dealers are required to ensure that the probiotic strains used, and the recommended doses are safe and meet the dosing recommendations stated in the evidence or references for the claimed intended effects for the target consumers (HSA, 2021).

In Thailand, manufacturers or importers may apply for the use of probiotic microorganisms other than those specified in the available list. Applications can be submitted using a form which can be accessed via: http: / / www.fda.moph.go.th/sites / food/manual/9.3.3-2_Probiotic(Eng). pdf. Information that must be submitted are as indicated in Table 2, including identity report, safety assessment results and characteristics of such probiotic microorganisms. The requirements are similar to those in the FAO/WHO Guidelines for the Evaluation of Probiotics in Food (FAO/WHO, 2002). Thai FDA has also stipulated that at least two well-designed human intervention studies from different institutes should be provided. Publications on clinical trials from outside of Thailand may be submitted for consideration (MoPH, 2011). Thai FDA has in place a process to review all applications. Upon confirmation that the application has provided all the required information as mentioned above, it is submitted to the FDA and subsequently submitted for expert consultation. All views are considered by the sub-committee and a decision made forwarded to the FDA.

Manufacturers may register a bacteria strain for use under supplemented food or as a health supplement in Vietnam. The VFA is the highest competent authority to evaluate and approve registration of products. Information required to be submitted are as indicated in Table 2. Permission for the use of the bacteria strain is given based on the strength of scientific evidence of the product or ingredient. Dossiers are to be submitted online. Upon evaluation by the regulatory authority, the applicant will be informed via online (Government of Vietnam, 2018; Au et al., 2019).

\section{Specific labelling requirements for probiotic products}

The probiotic regulation for food of Indonesia (NADFC, 2016) has listed the information that must be provided on the label of a food containing probiotics: clear description of the genus, species and strain; factual information about the benefits of the strain; the minimum number of live probiotic strains in terms of $\mathrm{cfu} / \mathrm{g}$ or $\mathrm{ml}$ at the end of shelf life; the serving size that should provide an effective minimum amount of probiotics to ensure the claim is in accordance with the result of clinical tests; health claims (if any); proper storage instructions; and address of the company that can be contacted for consumer information. 


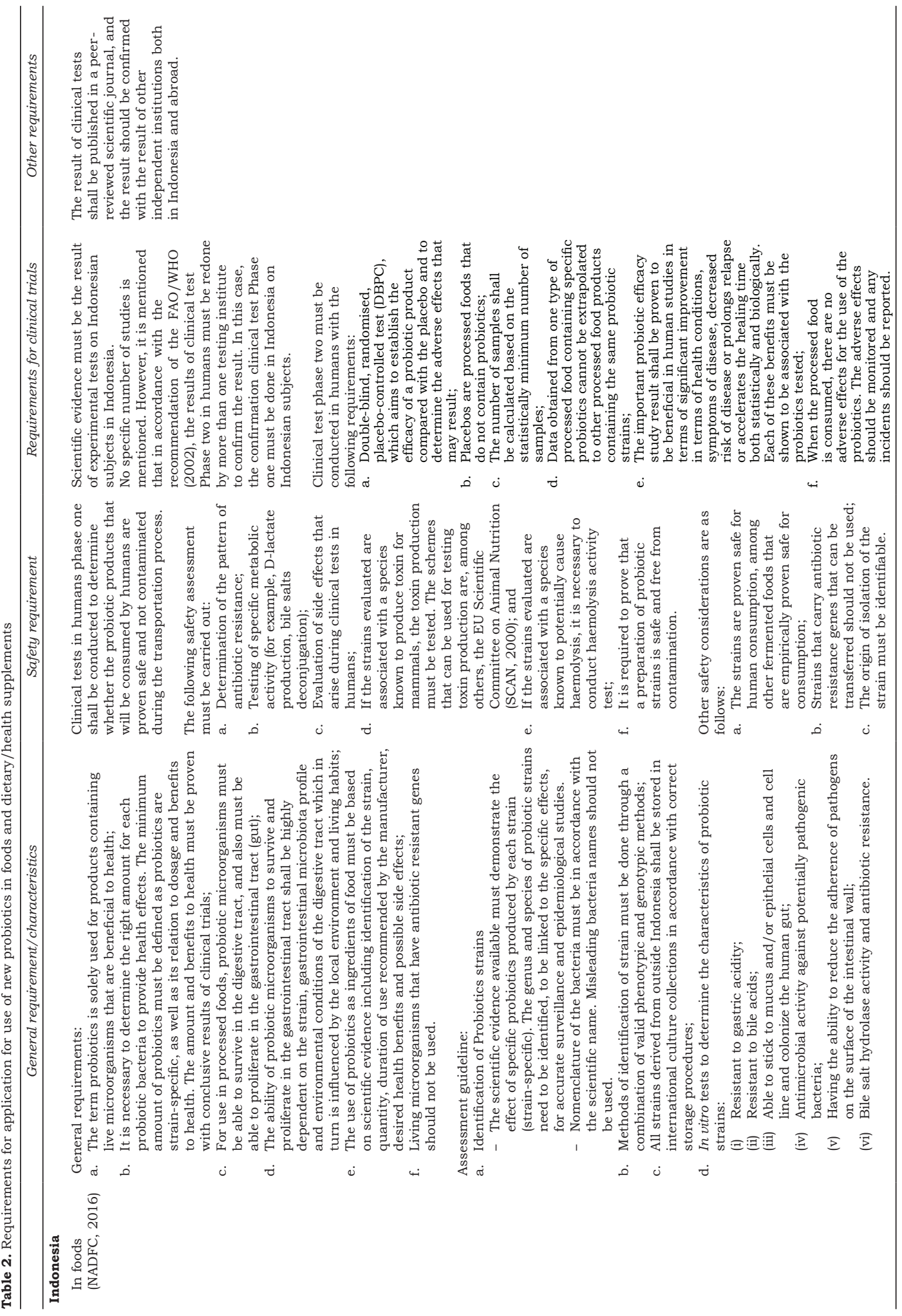




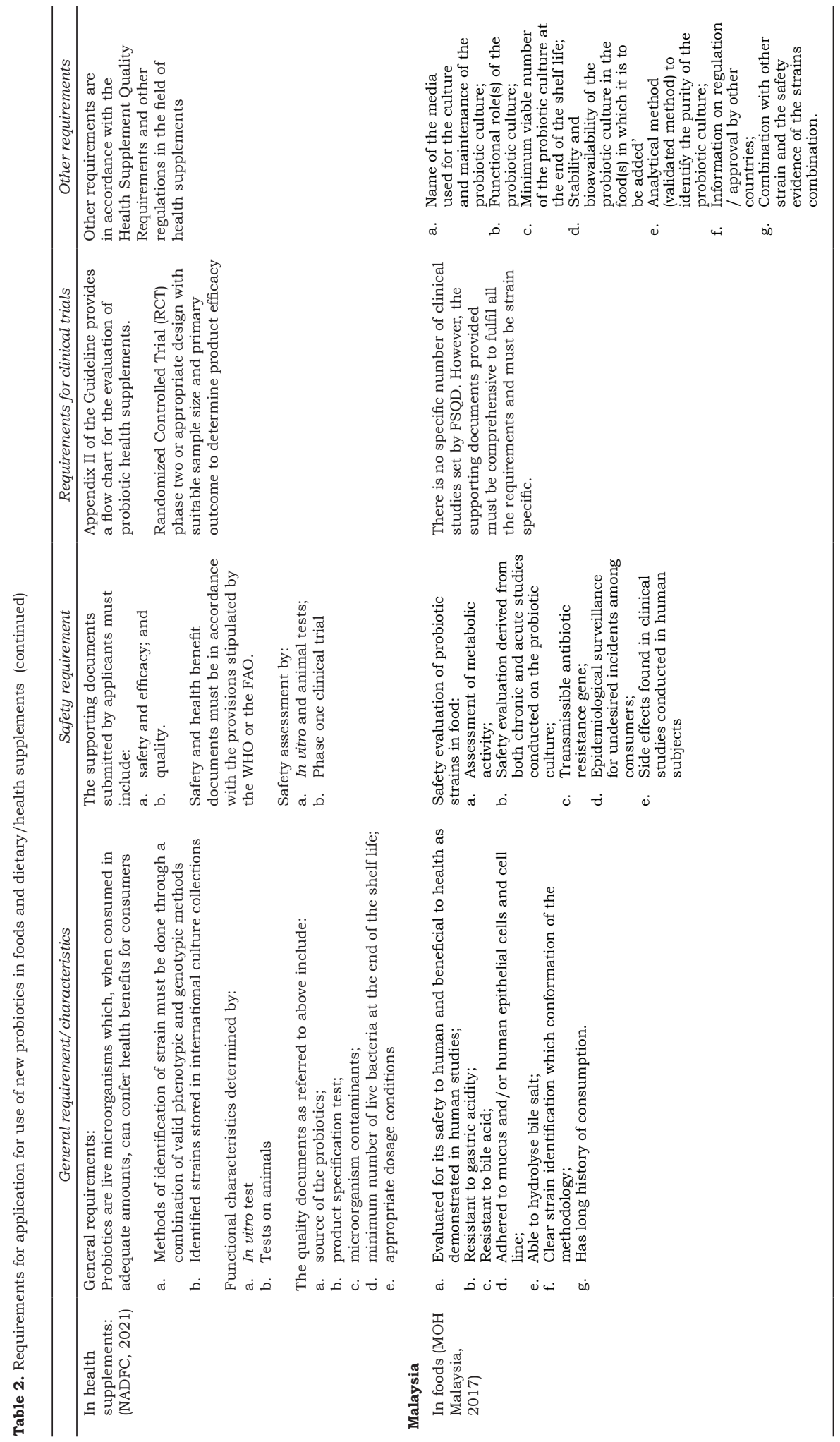




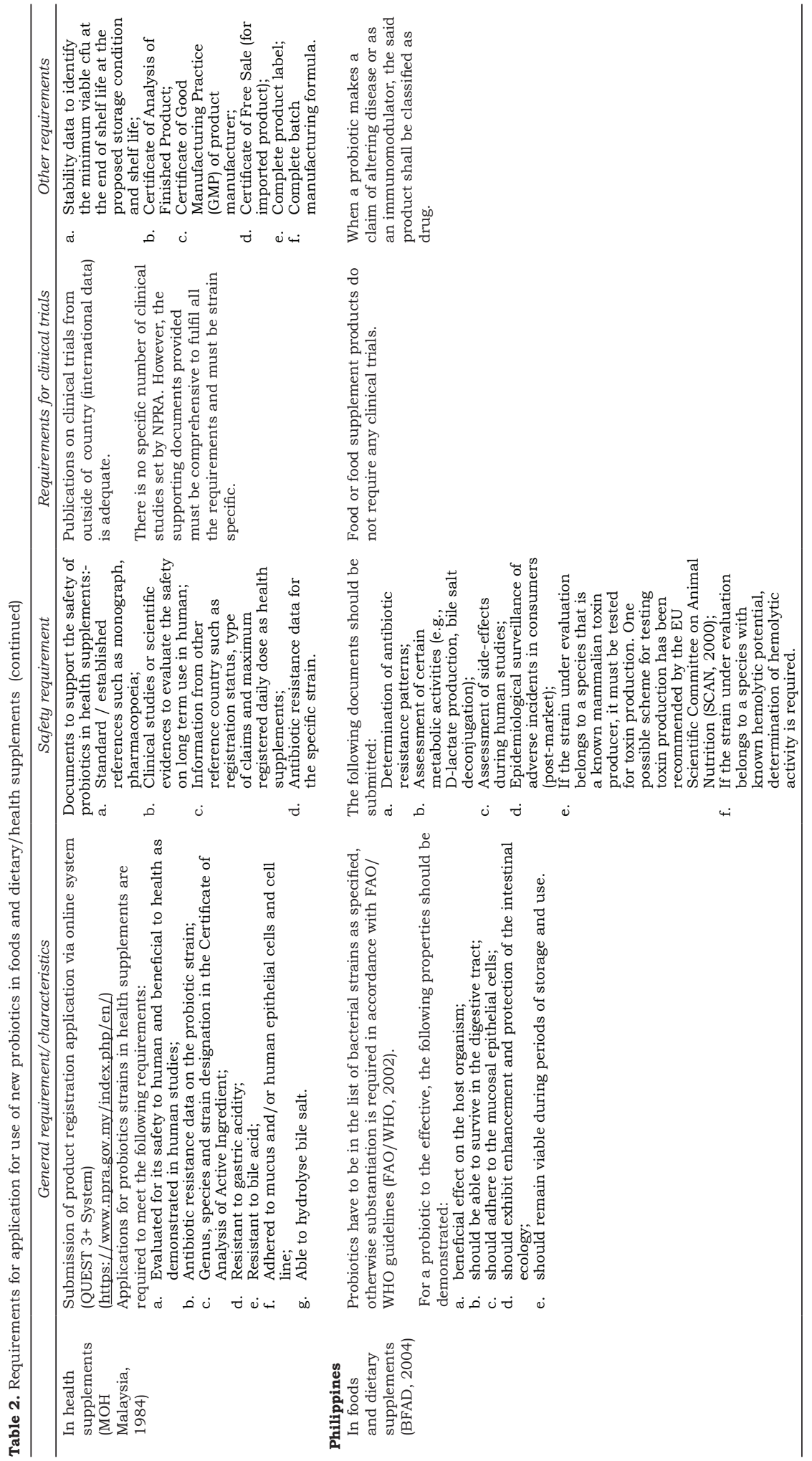




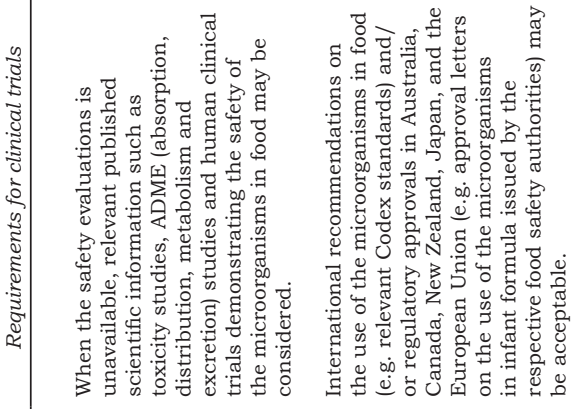

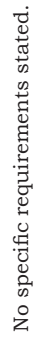

न तु

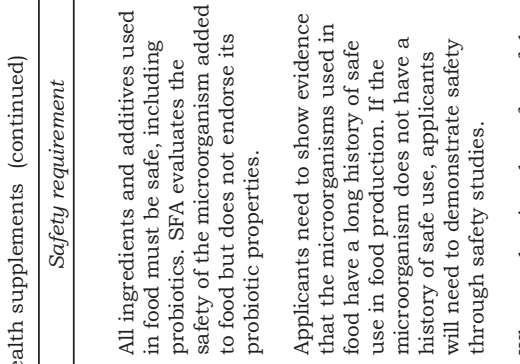

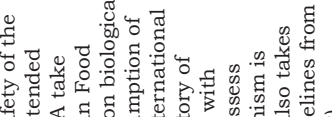

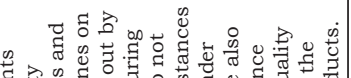

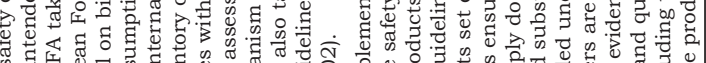

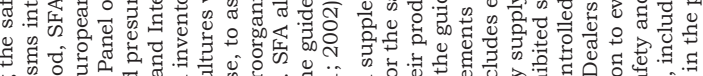
o. 击

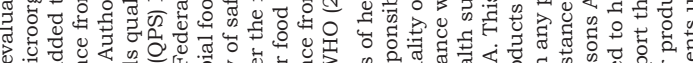

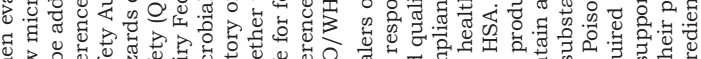

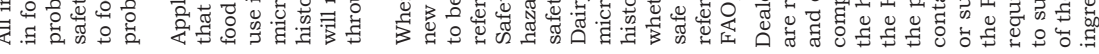
帝 (

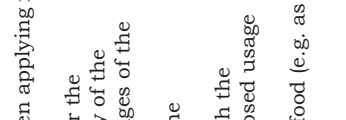




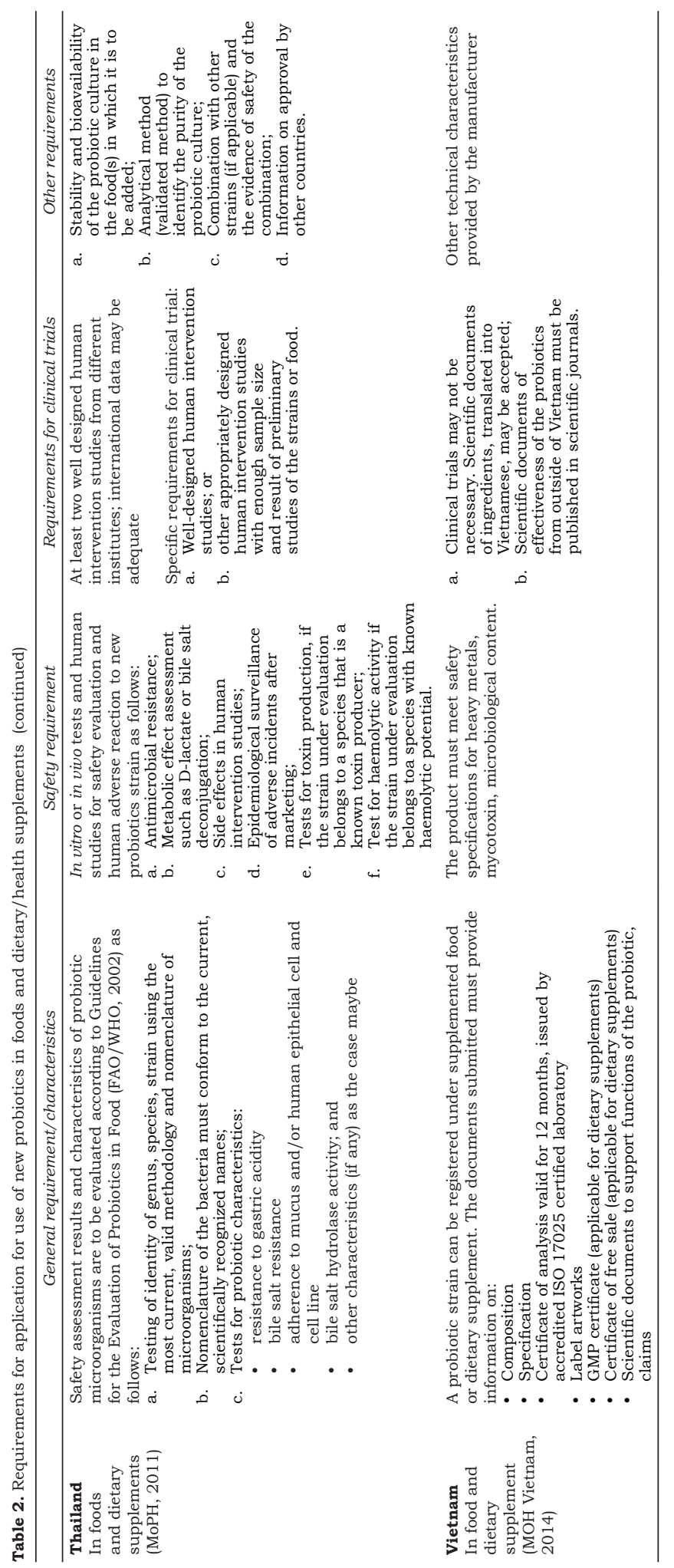


The same labelling requirements also apply to probiotic health supplements (NADFC, 2021).

For probiotic-containing foods in Malaysia, the Regulation 26A on probiotic culture has provided conditions dealing with labelling of foods with added probiotic cultures. These food products must be labelled with: the term probiotic cultures, as well as the genus, species and strain of the probiotic cultures; the quantity of the culture in $\mathrm{cfu} / \mathrm{ml}$ or cfu/g; direction for storage before and after package is opened. In addition, where the media used for propagation and maintenance of the probiotic cultures are derived from animal, the common name of such animal shall be stated on the food label. These labelling requirements are in addition to the general labelling requirements.

In Malaysia, all approved probiotic health supplements must adhere to the standard labelling requirement for health supplement as stipulated in the Drug Registration Guidance Document (GRDG) (MOH Malaysia, 2021). These include the usual information required for pharmaceutical products. NRPA highlights that all information on the label must be truthful and not misleading to the consumers.

Labelling aspects of probioticcontaining foods and dietary supplements in the Philippines should comply with the mandatory general labelling information required for a food. In addition to this, labels for a probiotic food or dietary supplement must also include the information on bacteria contents (genus, species, strain designation), minimum numbers of viable bacteria at end of shelf life, proper storage conditions and corporate contact details for consumer information.

In Singapore, both SFA and HSA have not specified any specific labelling requirements for probiotics in foods or health supplements. All prepacked food products and health supplements for sale in Singapore must be labelled according to the general labelling requirements for food and complementary health products prescribed by these regulatory authorities.

The label of all food products containing probiotic in Thailand must first adhere to the general labelling and nutrition labelling requirements of prepackaged foods in the country. The label of the product containing probiotics shall have the approval statement (if relevant), the term 'probiotic microorganism' or 'probiotics', as well as the genus, species and strain of the probiotics. For probiotic products carrying a health claim statement, the following additional information/statement must be provided: "This product is not intended to treat, heal, cure or prevent diseases"; amount to be consumed and time needed for health claim effect, instruction of use and appropriate condition for storage (MoPH, 2011).

For dietary supplements, depending on the ingredients contained therein, additional statements are required to appear on the label (MoPH, 2019). These statements include "Should eat varieties of five categories of food"; "No effect for prevention or cure diseases"; "Should not be consumed by children and pregnant women".

For a probiotic-containing food or supplement for sale in Vietnam, the manufacturer shall specify that the probiotic strain name as well as the amount per serving size or $100 \mathrm{~g}$ on the product label. For probiotic-containing product registered as supplemented food, there must be a phrase expressing the food group as "Supplemented foods" on the main part of the label, whereas for product registered as health 
supplement, there must be a phrase on main part of the label expressing the food group as "Health supplement" to distinguish ordinary foods from medicines. For probiotic registered as health supplement, the following warning statement must be given on the label: "This product is not a medicine, and it is not a substitute for medicines" (MOH Vietnam, 2014).

\section{Probiotic function and health claims and procedure for application}

Probiotic-containing foods in Indonesia are permitted to make health claims if they are supported by sufficient scientific evidence. The requirements for such applications are similar to those prescribed for applications for use of new probiotic strains (NADFC, 2016). Similarly, publications from clinical trials carried out on Indonesian population must be submitted to substantiate the application. The specific health claims approved may be listed on the label and used in advertising. It is pointed out that specific health claims for certain strains should not be used for other strains, and do not apply to a combination of various strains or synbiotic (probiotics with prebiotics).

Similarly, for health supplements in Indonesia, applications for products with probiotics may include claims. The requirements for such applications are similar to those prescribed for applications for use of new probiotic health supplements (NADFC, 2021).

In Malaysia, a pre-approved generic function claim for foods containing probiotics is permitted under the Regulations for probiotics, namely: "Probiotic cultures help in improving intestinal or gut function" or any other words of similar meaning (Table 3) $(\mathrm{MOH}$ Malaysia, 2017). Malaysia does not allow disease risk reduction health claims to be made on foods, although 'other function claims' may be considered, if supported by scientific substantiation.

Health claims on probiotic health supplements are permitted in Malaysia. Probiotics in health supplements can make general claims, functional claims and disease risk reduction claims if the relevant requirements for such claims stated in the Drug Registration Guidance Document (DRGD) can be fulfilled (MOH Malaysia, 2021). The current approved functional claim for probiotic is 'helps to improve a beneficial intestinal microflora' (Table 3). Companies applying for health claim must provide comprehensive publications on clinical trials to fulfil all the requirements and must be strain specific. Stability data is required to support the label claim amount of probiotic microorganism in the finished product at the proposed shelf life and storage condition.

The BFAD Circular in the Philippines has allowed the use of four pre-approved claims related to probiotics and can be reflected on the product labels, used for advertisement and product promotion (BFAD, 2004) (Table 3). These claims include enhancement of intestinal ecology, improvement of lactose malabsorption, improvement of digestion and aid to the enhancement of natural resistance to intestinal infections. Companies are permitted to apply for the use of these specified health claims on probiotics by going through the same review process as the procedure for evaluation of probiotics for food use.

In Singapore, only the list of preapproved health claims permitted under the Guide to Food Labelling and Advertisements (SFA, 2019) and regulation 9A of the Food Regulations (SFA, 2021) may be used on foods that meet the respective criteria. For probioticcontaining foods, four nutrient function claims relating to the role of probiotics in 
helping to maintain a healthy digestive system through suppressing the growth of harmful bacteria may be used (Table $3)$. The exact species of the probiotic present in the product must be specified on the label. The viable count of the probiotic present in the product that is able to bring about the claimed effect must also be indicated.

Health supplements in Singapore (including those containing probiotics) are not subject to pre-marketing approval by the HSA. The onus of ensuring that the health claims made for a probiotic health supplement is accurate, not false or misleading is on the dealer. All claims made should be adequately support by relevant evidence to provide truthful information to ensure consumers to make informed decisions when purchasing and consuming the products. In general, the health claims used on probiotic health supplements must be consistent with a product that is used to support or maintain the healthy functions of the human body. The claims made should not indicate that the product helps or implies that the product is necessary or play a role in diseased states. Claims such as "support/promote/maintain healthy digestion", or "support/promote/ maintain digestive health" may be used, but treatment claims such as "relief of constipation" or "treat diarrhoea" are not permitted (HSA, 2019).

Probiotic health claims are permitted in Thailand. A generic pre-approved health claim: "Beneficial microorganism to the body" or words of similar meaning may be used with prior approval by the Thai FDA (MoPH, 2011) (Table 3). Manufacturers or importers may apply for probiotics health claims using a form which can be accessed via: http://www.fda.moph.go.th/ sites / food/manual/9.2_checklist_ Health_claims(Eng)pdf. The regulation has provided clear guidelines for the criteria, procedure and conditions when submitting a health claim on probiotics (MoPH, 2011). Scientific substantiation of the intended claim should be obtained from well-designed human intervention studies from at least two different institutes. The guideline also listed the specific requirements for the clinical trials, including the details that should be covered in the design and results of the human intervention study.

There are no pre-approved claims, but companies may apply for health claims on probiotics in Vietnam. The application for health claims follows the same procedure and requirements for application of a probiotic strain to be registered for use under supplemented food or health supplement.

\section{DISCUSSION}

\section{Regulations in SEA countries for use of probiotics in foods and health supplements}

The six countries in this review have taken on different approaches in regulating the marketing and sale of probiotics in foods or dietary supplements. Only Indonesia, Malaysia, Philippines and Thailand have enacted specific regulations for this purpose. Two different divisions within the regulatory authorities in Indonesia and Malaysia are responsible for these products. In the Philippines and Thailand, both categories of products are controlled by the Food and Drugs Authority in these countries. Authorities in these countries have provided a legal definition of 'probiotics' which is basically similar to that of FAO/WHO consultation report (FAO/WHO, 2001).

Singapore and Vietnam have not enacted a specific regulation on probiotics but the use and sale of probiotics-containing foods and dietary supplements are permitted. There is also 
Table 3. List of health claims approved for probiotic-containing foods and dietary/health supplements in SEA countries

\begin{tabular}{|c|c|}
\hline & List of permitted health claims \\
\hline \multicolumn{2}{|l|}{ Indonesia } \\
\hline Foods & $\begin{array}{l}\text { No pre-approved claims. Applications may be made to BPOM, supported } \\
\text { by scientific evidence. Requirements are similar to those prescribed for } \\
\text { applications for use of new probiotic strains as indicated in Table } 2 \text {. }\end{array}$ \\
\hline Health supplements & $\begin{array}{l}\text { No pre-approved claims. Same as for foods, applications may be made to } \\
\text { BPOM, supported by scientific evidence. }\end{array}$ \\
\hline \multicolumn{2}{|l|}{ Malaysia } \\
\hline Foods & $\begin{array}{l}\text { A pre-approved function claim: } \\
\text { Probiotic cultures help in improving intestinal or gut function; words of } \\
\text { similar meaning may be used. } \\
\text { Malaysia does not allow disease risk reduction health claims to be made } \\
\text { on foods, although other function claims may be considered. }\end{array}$ \\
\hline Health supplements & $\begin{array}{l}\text { A pre-approved function claim: } \\
\text { Helps to improve a beneficial intestinal microflora. } \\
\text { Companies applying for health claims must provide comprehensive } \\
\text { publications to substantiate the proposed claims. }\end{array}$ \\
\hline \multicolumn{2}{|l|}{ Philippines } \\
\hline $\begin{array}{l}\text { Foods and } \\
\text { supplements }\end{array}$ & $\begin{array}{l}\text { Four (4) pre-approved function claims: } \\
\text { - Enhancement of intestinal ecology. } \\
\text { - Helping improve lactose malabsorption. } \\
\text { - Improving digestion. }\end{array}$ \\
\hline & $\begin{array}{l}\text { Companies may apply for use of health claims using the same process } \\
\text { as when applying for use of new probiotic strains. }\end{array}$ \\
\hline \multicolumn{2}{|l|}{ Singapore } \\
\hline & $\begin{array}{l}\text { The following five (5) pre-approved function claims relating to the role } \\
\text { of probiotics (exact name of probiotic must be specified) in helping to } \\
\text { maintain a healthy digestive system through suppressing the growth of } \\
\text { harmful bacteria may be used, as long as they are truthful and can be } \\
\text { substantiated. } \\
\text { - Helps to maintain a healthy digestive system. } \\
\text { - Helps in digestion. } \\
\text { - Helps to maintain a desirable balance of beneficial bacteria in the } \\
\text { Helps to suppress. } \\
\text { system, thereby helping to maintain a healthy digestive system. }\end{array}$ \\
\hline Health supplements & $\begin{array}{l}\text { No pe-approved list of permitted claims. Claims such as "support/ } \\
\text { promote/ maintain healthy digestion", or "support/promote/maintain } \\
\text { digestive health" may be used } \\
\text { Probiotic health supplements and their product claims are not subject } \\
\text { to pre- marketing approval by the HSA. The onus of ensuring that the } \\
\text { health claims made for a probiotic health supplement is accurate, not } \\
\text { false or misleading is on the dealer. }\end{array}$ \\
\hline \multicolumn{2}{|l|}{ Thailand } \\
\hline $\begin{array}{l}\text { Foods and } \\
\text { supplements }\end{array}$ & $\begin{array}{l}\text { A pre-approved function claim may be used: } \\
\text { Beneficial microorganism to the body. Words of similar meaning may be } \\
\text { used with prior approval by the Thai FDA. } \\
\text { Manufacturers or importers may apply for health claims with scientific } \\
\text { substantiation. }\end{array}$ \\
\hline
\end{tabular}


no legal definition of the term 'probiotics' in these two countries. In Singapore, the sale of probiotics in food and supplements are controlled by separate health authorities. In Vietnam, the sale of probiotics in foods and supplements is regulated by several ministries, including health and trade.

The microorganisms approved to be used as probiotics are not harmonised among the SEA countries. Malaysia listed a numbers of approved bacterial strains for use in foods, but there is no approved list for use in dietary supplements. Philippines and Thailand, on the other hand have published lists for probiotics approved to be used in foods and dietary supplements, but up to the genus and species level, respectively. Indonesia, Singapore and Vietnam do not have positive list of probiotics that may be used either for foods or dietary supplements. For countries with a positive list of bacteria strains, it is observed that the lists comprise mainly strains from Bifidobacterium $s p$. and Lactobacillus $s p$. Only Malaysia and Thailand have mandated that probiotic-containing products must contain a minimum number of probiotic microorganisms, i.e. at least $10^{6} \mathrm{cfu} / \mathrm{ml}$ or $\mathrm{cfu} / \mathrm{g}$ during the shelf life of such products.

All six countries in this review allow the application for new probiotics to be used, with varying requirements to be met, and have adopted differing regulatory approach. There are, however, several generally similar requirements among several the four countries with specific regulations, i.e. Indonesia, Malaysia, Philippines and Thailand. These four countries have provided clear guidelines to intending applicants. Clear identification of probiotic strains must be carried out. Tests to be carried out to determine the characteristics of probiotic strains include ability to survive in the digestive tract, adherence to the mucosal epithelial cells, and ability to hydrolyse bile salts. There are also rather similar safety assessments that must be conducted on the probiotic strains, e.g. determination of antibiotic resistance patterns and assessment of metabolic activities. Assessment of side effects of the cultures during clinical studies conducted in human subjects must also be conducted.

These four countries also require that all applications be accompanied by scientific evidence on functional roles or potential health benefits of the probiotic culture, demonstrated through human clinical studies. NADFC of Indonesia requires that these data must be obtained through local studies conducted on local population; details for the conduct of such clinical trials are provided in the regulation. The other three countries accept international data published in peer-reviewed journals.

Pre-approved generic function/ health claims related to intestinal or gut function; or digestive health/ healthy digestive system; or intestinal microflora/microorganisms/ecology; or desirable balance of beneficial bacteria are permitted for use in foods and health supplements containing probiotics in Malaysia, Philippines, Singapore and Thailand. Applications for additional health claims can be submitted to the regulatory authorities in all countries except Malaysia. Applications must be accompanied by scientific evidence obtained from human clinical trials. In the case of NAFDC, such data must be obtained through local studies conducted on Indonesian population. However, there is a lack of clarity in the requirements for application in some countries with no clear regulation for probiotic, such as Vietnam.

Countries in the review have adopted differing approaches with regard to the specific labelling requirement for 
products containing probiotics. Except for Singapore, all the other five countries (Indonesia, Malaysia, Philippines, Thailand, Vietnam) require the product label to have clear identification of the genus, species and strain of the probiotics, the number of live microorganisms in terms of $\mathrm{cfu} / \mathrm{g}$ or $\mathrm{ml}$ at the end of shelf life, as well as storage instructions. Singapore, on the other hand, does not have specific labelling requirements for probiotic containing foods or health supplements.

In addition, Thailand and Vietnam have mandated the requirement to have cautionary statements for probiotic health supplement products, for example that the supplement is not a medicine and not a substitute for medication.

\section{Global probiotic regulations}

In a review of 11 Asian countries and Australia and New Zealand, Au et al (2019) had demonstrated that there is no harmonised regulations or guidelines on probiotics in foods and dietary supplements. Each country has its unique regulatory approach to these products. Probiotic-containing foods have also been placed in different categories, e.g. general foods (Indonesia, Malaysia, Singapore, Thailand), functional foods (China, Vietnam), nutraceuticals (India), health supplements (Indonesia, Malaysia, Singapore, Vietnam), Food for Specified Health Use (FOSHU) (Japan), health foods (Taiwan) and novel foods (China, India, Australia New Zealand). There are also divergent approaches in the other aspects of the regulatory framework including approved probiotic strains, permitted claims, procedure for application for new probiotic strains.

More recently, Nomoto (2021) has provided a review of the status of probiotic regulations in several continents. In North America, only Canada and Brazil have enacted regulations for these beneficial microorganisms. In Europe region, there is no specific regulations or guidelines in the European Union, although some countries in the region have provided for this. These countries include Italy, Czech Republic and the Netherlands. In Asia, China, Korea and India have legislations regulating probiotics. There is no specific probiotic regulation in Japan, but the Food for Specified Health Uses (FOSHU) system permits claims related to gastrointestinal tract using probiotics Lactobacilli and Bifidobacterium (Au et al, 2019; Iwatani \& Yamamoto, 2019).

\section{Harmonisation of probiotic regulations in SEA countries}

Several years ago, Arora \& Baldi (2015) had pointed out that probiotic products have been introduced into the international market as food supplements, dietary supplements, natural health products, functional foods and many other categories. The status of probiotic-based products was full of ambiguities because various regulatory agencies in different countries are defining and categorising probiotics differently. As a result, there was considerable confusion and scepticism amongst regulatory bodies, producers and consumers, for the associated claims of probiotic products. A single definition of probiotics and use of consistent terminologies were lacking. There was also a lack of regulatory framework and harmonisation of guidelines on an international basis. The authors called for a common regulatory framework to enable future safe and efficacious use of probiotics.

This review has indicated that there is no harmonised probiotic regulations, either for use in foods or dietary supplements in SEA countries. 
The diverse implementation of probiotic regulations across countries creates inconsistencies and difficulties for all key stakeholders including government authorities, academia, industry and consumers. Without a common understanding and harmonised use of the term 'probiotic' and characteristics of such products, there could be misuse of the term and products not meeting the required criteria may be available to consumers.

Having a harmonised regulation on probiotics in the region is expected to be beneficial to the trading of probiotic products within the SEA region as well as outside the region. It will also have a positive impact on research and development of probiotics by the academia and the industry. Consumer confidence on probiotic products will also be enhanced.

In this regard, the SEA PROBIOTICS SREN has provided a platform for discussion among key stakeholders to explore opportunities for harmonisation of some aspects of the regulatory framework for probiotics in SEA countries. It was felt that five aspects of the probiotic regulations in foods and supplements could be considered, namely: definition of probiotics, positive list of probiotics, general health claims on probiotics, labelling of probiotics and procedure for applications for use of new probiotic strains. The Network is currently working on developing a common framework and guideline for the evaluation of probiotic cultures for use in foods, beverages and dietary supplements in the region. The guideline will include the following aspects of the probiotic strains: identification and nomenclature, characteristics, safety evaluation including in humans and functional role/beneficial health effects.

Recognising that there are no harmonised regulations on probiotics in foods or dietary supplements globally, there has been an effort to develop a harmonised probiotic guideline for use in foods and dietary supplements within the Codex Alimentarius system. At the last session of the Codex Committee on Nutrition and Foods for Special Dietary Uses (CCNFSDU) in 2019, a Discussion Paper on Harmonised Probiotic Guidelines for Use in Foods and Dietary Supplements (CX/NFSDU 19/41/11) (FAO/WHO, 2019a) was tabled for discussion. This discussion paper has been revised jointly by Argentina and Malaysia, based on comments made by delegations during the CCNFSDU session in 2019 (FAO/QWHO, 2019b), and is expected to be considered in the next session of the CCNFSDU at the end of 2022 .

\section{CONCLUSION}

All indications are that the demand for probiotics in foods and beverages and dietary supplements will continue to increase in the SEA region. It is important for countries to have clear regulatory control, to ensure consumers have access to safe and efficacious probiotic containing foods or dietary supplements. Clear regulations or guidelines by authorities will provide guidance to consumers on choosing genuine probiotic-containing products. Hopefully, products that do not meet the criteria for probiotics will eventually be weeded out. Similarly, this will enable the industry to have a clear understanding of the requirements when submitting new probiotic strains for approval. Information from this review can serve as reference to countries in the region intending to establish regulations or update existing regulations.

The review has indicated that only four countries in SEA region have enacted clear regulations for the use of probiotics 
in foods or dietary supplements. There are significant benefits for all stakeholders if there are harmonised regulations for use in the region. The SEA PROBIOTICS SREN will continue to make effort to harmonise some aspects of the probiotic regulations. The Network will also continue to provide a platform for the key stakeholders in the region (from government, academia, professional organization and private sector) to share updates on scientific and regulatory aspects of probiotics and microbiome research. In the meantime, it is hoped that the proposed harmonised probiotic guideline will be accepted as new work in the Codex Alimentarius system.

Further development of probiotics in the region can continue to improve and progress so that more probiotic products can be made available for the health and wellbeing of the consumers. This would require capacity building in research and development, regulatory development and harmonisation, and even consumer education on appropriate choice and use of probiotic products. Collaboration among the main players, namely the regulatory authorities, the research groups, professional bodies and the relevant industry will facilitate these development.

\section{Acknowledgement}

This work was conducted by the SEA PROBIOTICS SREN. The authors acknowledge the funds from DuPont Nutrition \& Biosciences for organising meetings of SREN to enable exchange of views and experiences of stakeholders on scientific and regulatory aspects of probiotics, to enable this work to be carried out. The authors also acknowledge the following regulatory officials and experts for providing input to the template and verifying the compiled information: Yusra Egayanti, Tetty Helfery Sihombing and Muhammad Nur Hasan Syah (Indonesia); Raizawanis Abdul Rahman, Rosilawati Ahmad and Karen Wong (Malaysia); Maria Victoria D Pinion (Philippines); Tan Yi Ling and Ng Ling Ling (Singapore); Malee Jirawongsy (Thailand); Le Hoang Vinh and Tran Khanh Van (Vietnam).

\section{Authors' contributions}

All authors contributed to the conceptualisation of paper, obtained regulations for analysis, analysed available information, drafted manuscript, finalised manuscript for publication.

\section{Conflict of interest}

TES and $\mathrm{H}$ declare that they have no conflicts of interest; CASS is the staff member of DuPont Nutrition \& Biosciences.

\section{References}

Arora M \& Baldi A (2015). Regulatory categories of probiotics across the globe: A review representing existing and recommended categorization. Indian $J$ Medic Microbiol 33(Supplement 1):S2-10. https://doi. org/ 10.4103/0255-0857.150868

Au C, Lin S, Shao W, Jin S, Wen Y, Singh J, Basuki V, Tanaka H, Geun EJ, Tee ES, Tan JD, Chen MJ, Jirawongsy M, Vinh LH, Gray C \& Lee YK (2019). Probiotics regulation in Asian and Australiasian countries. In: Vinderola G, Ouwehand AC, Salminen S \& von Wright A (eds). Lactic Acid Bacteria. Microbiological and Functional Aspects. Fifth Edn. (Chapter 38, pp 633-682). CRC Press, Boca Raton.

BFAD (2004). Guidelines on Probiotics. Bureau Circular No. 16s. 2004. Bureau of Food and Drugs, Department of Health, Republic of the Philippines, Alabang.

FAO/WHO (2001). Health and Nutrition Properties of Probiotics in Food including Powder Milk with Live Lactic Acid Bacteria. Report of a Joint FAO/WHO Expert Consultation on Evaluation of Health and Nutritional Properties of Probiotics in Food including Powder Milk with Live Lactic Acid Bacteria. Cordoba, Argentina 1-4 October 2001. In: FAO/WHO (2006). Probiotics in foodHealth and nutrition properties and guidelines for evaluation. FAO Food and Nutrition Paper 85. World Health Organization and Food and Agriculture Organization of the United Nations, Rome. From: https://www.fao.org/3/a0512e/ a0512e.pdf [Retrieved December 4 2021].

FAO/WHO (2002). Guidelines for the Evaluation of Probiotics in Food. Report of a Joint FAO/WHO Working Group on Drafting Guidelines for the Evaluation of Probiotics in Food. London Ontario, Canada. In: FAO/ WHO (2006). Probiotics in food - Health and nutrition properties and guidelines for evaluation. FAO Food and Nutrition Paper 85. World Health Organization and Food and Agriculture Organization of the United Nations, Rome. From: https://www.fao.org/3/a0512e/ a0512e.pdf [Retrieved December 4 2021]. 
FAO/WHO (2019a). Discussion Paper on Harmonized Probiotic Guidelines for Use in Foods and Dietary Supplements (CX/NFSDU 19/41/11). Tabled at the Forty-First Session of the Codex Committee on Nutrition and Foods for Special Dietary Uses, Düsseldorf, Germany 24 - 29 November 2019. Food and Agriculture Organization of the United Nations, Rome. From: https://www.fao. org/fao-who-codexalimentarius/sh-proxy / en / ? lnk=1\&url=https $\% 253 \mathrm{~A} \% 252 \mathrm{~F} \% 252$ Fworkspace.fao.org $\% 252 \mathrm{Fsites} \% 252 \mathrm{~F}$ codex $\% 252 \mathrm{FMeeting} \% 252 \mathrm{FCX}-720$ 41\%252FWD\%252Fnf41_11e.pdf [Retrieved December 4 2021].

FAO/WHO (2019b). Report of the Forty-First Session of the Codex Committee on Nutrition and Foods for Special Dietary Uses, Düsseldorf, Germany 24 - 29 November 2019 (pp 2021). Food and Agriculture Organization of the United Nations, Rome. From: https://www. fao.org/fao-who-codexalimentarius/sh-proxy/ en / ?lnk=1 \&url=https \% 253 A \% 252 F\% 252 Fworkspace.fao.org $\% 252$ Fsites $\% 252$ Fcodex $\% 2$ 52FMeetings $\% 252$ FCX-720-41\%252FReport $\%$ 252FAdoption\%252FREP20_NFSDUe_Rev.pdf [Retrieved December 4 2021].

FDA (2016). Procedure for the Use of Electronic Registration (E-Registration) System for Prepackaged Processed Food Products. Food and Drug Administration Philippines. From: https://www.fda.gov.ph/wp-content/ uploads / $2021 / 03 /$ F D A - Circular No.-2016-014.pdf [Retrieved December 4 2021].

Government of Vietnam (2018). Elaboration of Some Articles of the Law of Food Safety. Decree No. 15/2018/ND-CP. Socialist Republic of Vietnam, Hanoi. From: http:// vanban.chinhphu.vn/portal/page/portal/ chinhphu/hethongvanban?class_id $=1 \&_{-}$ page $=1 \&$ mode $=$ detail\&document_id $=192829$ [Retrieved December 4 2021].

Guarner F \& Schaafsma GJ (1998). Probiotics. Int J Food Microbiol 39(3): 237-238. https://doi. org/10.1016/S0168-1605(97)00136-0

Hill C, Guarner F, Reid G, Gibson GR, Merenstein DJ, Pot B, Morelli L, Canani RB, Flint HJ, Salminen S, Calder PC \& Sanders ME (2014). The International Scientific Association for Probiotics and Prebiotics consensus statement on the scope and appropriate use of the term probiotic. Nat Rev Gastroenterol Hepatol 11:506-514.

Iwatani S \& Yamamoto N (2019). Functional food products in Japan: A review. Food Sci Hum Wellness 8:96-101.
HSA (2021). In: Regulatory overview of health supplements. Health Sciences Authority, Singapore. From: https://www.hsa.gov.sg/ health-supplements/overview [Retrieved December 4 2021].

HSA (2019). List of health supplement claims. Health Sciences Authority, Singapore. From: https: / / www.hsa.gov.sg/docs / defaultsource/hprg-tmhs/hsclaimslist.pdf [Retrieved December 4 2021].

MOH Malaysia (1984). Control of Drugs and Cosmetics Regulations 1984. National Pharmaceutical Regulatory Agency, Ministry of Health Malaysia, Petaling Jaya. From: https: / www.pharmacy.gov.my/v2/sites / default/files/document-upload/control-drugsand-cosmetics-regulation-1984.pdf [Retrieved December 4 2021].

MOH Malaysia (2017). Regulation 26A, Probiotic Cultures. Food Regulations 1985. Food Safety \& Quality Division, Ministry of Health Malaysia, Putrajaya. From: http://fsq.moh.gov.my/v6/ xs/page.php?id=72 [Retrieved December 4 2021].

MOH Malaysia (2021). Drug Registration Guidance Document (DRGD). $3^{\text {rd }}$ Edition, first revision July 2021. National Pharmaceutical Regulatory Agency, Ministry of Health Malaysia, Petaling Jaya. From: https://www.npra.gov.my/index. php/en/component/sppagebuilder/925-drugregistration-guidance-document-drgd.html [Retrieved December 4 2021].

MoPH (2011). Notification of the Ministry of Public Health No. 339 Re: Use of Probiotic Microorganisms in Foods. Ministry of Public Health, Thailand. From: http://food.fda.moph. go.th/law/data/announ_moph/V.English / No.\%20339\%20Use $\% 20$ of $\% 20$ Probiotic $\% 20$ Microorganisms\%20in\%20Foods.pdf [Retrieved December 4 2021].

MoPH (2012). Notification of the Ministry of Public Health No. 346 Re: Use of Probiotic Microorganisms in Foods (No.2). Ministry of Public Health, Thailand. From: http://food. fda.moph.go.th/law/data/announ_moph/V. English / No.\%20346\%20Use\%20 of\% 20 Probiotic\%20Microorganis ms \% 20 in \% 20 Foods\%20(No.2).pdf [Retrieved December 4 2021].

MoPH (2019). Notification of the Ministry of Public Health (No. 405). Re: Food Supplements (No. 3). Ministry of Public Health, Thailand. From: http://food.fda.moph.go.th/law/data/ announ_moph/V.English/No.405.pdf [Retrieved December 4 2021]. 
MOH Vietnam (2014). Regulating the Management of Functional Foods. Circular No: 43/2014/ TT-BYT. Ministry of Health, Socialist Republic of Vietnam, Hanoi. From: http:// vanban.chinhphu.vn/portal/page/portal/ chinhphu/hethongvanban?class_id $=1 \&_{\text {_ }}$ page $=1 \&$ mode $=$ detail\&document_id $=178185$ (Retrieved December 4 2021).

NADFC (2016). Regulation No. 13 / 2016 concerning Controlling of Claims on Processed Food Label and Advertising, specifically Annex XI on Guidelines for the Assessment of the Use of Probiotics in Processed Food. National Agency for Drug and Food Control of the Republic of Indonesia, Jakarta. Original Indonesian language document is accessible from: https://standarpangan.pom.go.id/dokumen/ peraturan / $2016 / \mathrm{PerKa}$ _BPOM_No_13_ Tahun_2016_tentang_Klaim_pada_Label_dan_ Iklan_Pangan_Olahan.pdf [Retrieved December 4 2021].

NADFC (2021). Regulation No. 17/ 2021. Pedoman Penilaian Produk Suplemen Kesehatan MengandungProbiotik(Guidelines on Evaluation of Health Supplement Products Containing Probiotics). National Agency for Drug and Food Control of the Republic of Indonesia, Jakarta. Original Indonesian language document is accessible from: https://jdih.pom.go.id/ download/product/1270/17/2021 [Retrieved December 4 2021].

Nomoto J (2021) Case Study 4: Probiotics. From the Current Idea to Future Development Prospects. In: Tee ES, Wong J, Chan P (eds). Functional Foods Monograph (pp 59-70), ILSI SEA Region Mongoraph Series, International Life Sciences Institute Southeast Asia Region, Singapore.
Mordor Intelligence (2021). In: Asia-Pacific Probiotics Market - Growth, Trends, Covid-19 Impact, and Forecasts (2021 - 2026). From: https: / www.mordorintelligence.com / industry-reports / asia-pacific-probioticsmarket-industry [Retrieved December 4 2021].

SCAN (2000). Opinion of The Scientific Committee on Animal Nutrition on the Safety of Use of Bacillus Species in Animal Nutrition. European Commission. Health \& Consumer Protection Directorate-General. From: https://ec.europa. $\mathrm{eu} /$ food/system/files/2020-12/sci-com_scanold_report_out41.pdf. [Retrieved December 4 2021].

SFA (2019). A Guide to Food Labelling and Advertisements. Singapore Food Agency, Singapore. From: https://www.sfa. gov.sg/docs/default-source/tools-andresources / resources-for-businesses / aguidetofoodlabellingandadvertisements.pdf [Retrieved December 4 2021].

SFA (2021). Sale of Food Act [Chapter 283, section 56(1)] and Food Regulations. Singapore Food Agency https://www.sfa.gov.sg/docs/defaultsource/legislation/sale-of-food-act/food regulations.pdf [Retrieved December 4 2021]. 